Revista Latinoamericana de la Papa 23 (1): 14 - 34, 2019

ISSN: 1853-4961

http://ojs.papaslatinas.org/index.php/rev-alap/index

\title{
Selección de bacterias endófitas tipo Bacillus como promotoras de crecimiento en el cultivo de papa variedad Huaycha (Solanum tuberosum subsp. andigena)
}

\author{
N. Rocha ${ }^{1}$; M. Claros²; J. J. Calisaya ${ }^{2}$; N. Ortuño ${ }^{3 / *}$
}

Recibido: $21 / 04 / 2019$

Aceptado: 04/06/2019

Accesible en línea: Junio de 2019

\section{Resumen}

Con el objetivo de evaluar bacterias endófitas de tipo Bacillus, aisladas de papas nativas como promotores de crecimiento vegetal en el cultivo de papa Huaycha, para el desarrollo de bioinsumos, se activaron 39 aislados bacterianos in-vitro, de los cuales 30 resultaron ser tipo Bacillus. Estos, para su evaluación fueron inoculados en invernadero, bajo el diseño de bloques al azar con 6 repeticiones en dos etapas. Las variables de respuesta fueron: altura de planta, longitud de raíz, peso de raíz, volumen de raíz, número de tubérculos, peso de tubérculos y rendimiento de tubérculo. Fueron seleccionados 11 aislados como mejores, debido a que favorecieron en mayor proporción el desarrollo de las características fenotípicas del cultivo de la papa $(13,19,27,32,38,45,46,47,138,146$ y 150), las cuales se evaluaron in-vitro, resultando 9 fijadoras de nitrógeno, 5 solubilizadoras de fósforo y 3 productoras de ácido indol acético. Los aislados 27 y 146 cumplieron con tres funciones (fijadoras de $\mathrm{N}$, solubilizadoras de $\mathrm{P}$ y productoras de AIA) y para la caracterización bioquímica demostraron que corresponden al género Bacillus. Para culminar en la segunda etapa, se volvieron a evaluar seleccionando los mejores aislados $(19,146,45,47$ y 150 incluyendo el inóculo comercial B. subtilis) en invernadero, donde se presentó mayor efecto sobre el desarrollo de la planta. Destacándose el aislado 45, por presentar mayor altura de planta y desarrollo de tubérculo con un rendimiento de 3 t/ha de papa.

Palabras claves adicionales: Fijadoras, solubilizadoras, aislados, PGPR, endófitas.

Selection of endophytes bacteria type Bacillus as promoters of growth in the culture of papa variety Huaycha (Solanum tuberosum ssp. andigena)

\section{Summary}

With the objective of evaluating endophytic bacteria Bacillus type, isolated out native potato plant growth promoters, the Huaycha variety cultivation for the development of bioproducts, 39 were activated in-vitro bacterial isolates, of which 30 were found to be Bacillus type. For evaluation purposes, these types were inoculated in greenhouse conditions under completely randomized design with 6 repetitions in two stages blocks. The response variables were: plant height, root size, root weight, root volume, number of tubers, tuber weight and tuber yield. They were selected 11 isolated as better because they

\footnotetext{
Autor para correspondencia. E-mail: n.ortuno@umss.edu.bo

Estudiante FCAP-UMSS, Cochabamba, Bolivia.

Consultores independientes, Cochabamba, Bolivia.

CITTMACC-FCAP-UMSS, Cochabamba, Bolivia.
} 
favored greater extent the development of the phenotypic characteristics of the potato crop $(13,19,27,32,38,45,46,47,138,146$ and 150), the which they were evaluated in-vitro, resulting nitrogen fixers 9,$5 ; 3$ phosphorus solubilizing and 3 indol-acetic acid producers. Isolates 27 and 146 met the three functions (fixing of $\mathrm{N}, \mathrm{P}$ solubilizing and producing AIA) and biochemical characterization showed that correspond to the genus Bacillus. Culminating in the second stage, they were reassessed selecting the best isolates $(19,146$, 45, 47 and 150 including the commercial inoculum Bs) in greenhouse, where he presented greater effect on plant development. Stading out isolated 45, to present greater plant height and tuber development with a yield of 3 t/ha of potatoes.

Additional keywords: Fixers, solubilizers, isolated, PGPR, endophytes.

\section{Introducción}

La papa (Solanum tuberosum) es el cuarto cultivo de importancia mundial después del trigo, arroz y el maíz, es parte de la seguridad alimentaria, económica y cultural de vastas poblaciones y su contribución a la alimentación ha sido tan importante que la UNESCO ha declarado al 2008 como "Año Internacional de la papa" (Pérez, 2008). Debido a la calidad nutricional como proteínas, calorías, hidratos de carbono, Potasio y vitamina B6.

En Bolivia el cultivo de la papa es importante desde el punto de vista histórico, social, económico y alimenticio. Actualmente, la producción de papa involucra a más de 200000 familias que cultivan un total de 129230 ha. En 7 de los 9 departamentos del país, la producción anual de la papa es de 827690 t y el rendimiento promedio es de 5,6 t/ha (Crespo y Bellot, 2003).

Si bien el uso de los fertilizantes químicos incrementa los rendimientos, el uso intensivo de los mismos ha causado alteraciones en el medio ambiente y la salud humana, por lo que la población exige productos agrícolas saludables. Razón por la cual, la producción agrícola actual con problemas en el consumo de agua, fertilizantes y pesticidas, requiere de estrategias donde éstos insumos se reduzcan, para asegurar el rendimiento vegetal a un costo relativamente bajo, sin deterioro de la fertilidad del suelo ni el medio ambiente.

Ante la necesidad y la demanda por los productores del país boliviano se ha generado la necesidad de tecnología alternativa a los insumos agrícolas o agroquímicos, para lo cual se está explorando los recursos microbiológicos y otros disponibles en el país, para desarrollar bioplaguicidas y biofertilizantes. Este tipo de tecnología permite ser usada en la agricultura orgánica o en una producción convencional, donde se puede reducir el uso de agroquímicos (Ortuño et al., 2010).

El caso de las bacterias de tipo Bacillus que presentan una elevada tolerancia térmica, un rápido desarrollo en medio líquido y una formación de esporas altamente resistentes. Además, tienen efecto en la promoción de crecimiento de las plantas, características que las hacen apropiadas para la formulación de productos viables y estables para el desarrollo de bioinsumos que promueven en crecimiento vegetal.

Por todo lo anteriormente mencionado en el presente trabajo de investigación, en búsqueda de estrategias de manejo sustentable, se realizó la selección de bacterias endófitas tipo Bacillus aisladas de papas nativas, como promotoras de 
crecimiento vegetal, para aportar al uso de alternativas agroecológicas (bioinsumos) en el cultivo de papa. Por lo tanto se seleccionar bacterias endófitas del tipo Bacillus, aisladas de papas nativas, como promotoras de crecimiento vegetal en el cultivo de la papa variedad Huaycha, para el desarrollo de bioinsumos.

\section{Materiales y Métodos}

El trabajo se realizó en tres etapas, las cuales se describen a continuación:

\section{Primera etapa}

Activación de las bacterias endófitas provenientes del cultivo de papas nativas

Para la activar las cepas se preparó el medio de cultivo líquido TSB (Triptona Soya Agar), con la ayuda de un dispensador se distribuyó $6 \mathrm{~mL}$ del medio de cultivo en tubos de ensayo, los cuales se autoclavaron por $15 \mathrm{~min}$ a $121^{\circ} \mathrm{C}$ a 20 psi. Posteriormente, bajo una cámara de flujo laminar y en condiciones de asepsia, se inoculó cada bacteria a un tubo de ensayo debidamente identificado, los cuales se llevaron a un agitador orbital con un movimiento constante de $100 \mathrm{rpm}$ durante 1 semana, a temperatura ambiente.

\section{Selección in-vitro de bacterias tipo Bacillus}

Para la selección in-vitro de bacterias tipo Bacillus se utilizó el protocolo de Pérez et al., (2004). Para lo cual, en una cámara de flujo laminar en condiciones de asepsia, una vez reactivadas las cepas bacterianas se dispensó $1 \mathrm{~mL}$ de muestra de cada cepa en tubos eppendorf, correctamente identificados, para luego someter a un choque térmico por 15 minutos a una temperatura constante de $80^{\circ} \mathrm{C}$ para eliminar aquellas bacterias que no sean del tipo Bacillus. El medio de cultivo TSA (soya triptona agar), fue preparado con un día de anticipación y dispensado en placas Petri. Las placas Petri fueron divididas en 16 cuadrantes identificados cada uno. Bajo una cámara de flujo y en condiciones de asepsia, se sembró con la ayuda de un asa metálica cada una de las muestras extraídas de los tubos eppendorf. Posteriormente las placas fueron incubadas a $28^{\circ} \mathrm{C}$ durante 48 horas. Los que presentaron crecimiento de colonias en el medio fueron seleccionadas como Bacillus.

\section{Evaluación del ensayo en invernadero con las cepas seleccionadas}

Esterilización del sustrato y desinfección de invernadero. El sustrato fue constituido por arena, materia orgánica, lama y cascarilla de arroz en una relación de $1: 1: 1: 2$ el cual fue esterilizado a $121^{\circ} \mathrm{C}$ por 120 minutos con vapor de agua a 1.5 atmósferas de presión.

Para la desinfección de invernadero se realizó un aseo general y minucioso a los mesones, piso, macetas, identificadores y todo lo necesario a usar. Para el ensayo se utilizó macetas de $2 \mathrm{Kg}$ de capacidad con sustrato estéril y humedad en capacidad de campo.

Como inóculo se utilizaron las cepas bacterianas que fueron reactivadas $y$ desarrolladas en el medio de cultivo liquido TSB, el cual fue dispensado con ayuda de una micropipeta utilizando 500 $\mu \mathrm{L}$ por tubérculo (semilla), para lo cual se tuvo el cuidado de posibles contaminaciones o salpicaduras de una maceta a otra.

Los tratamientos lo constituyeron 30 aislados bacterianos provenientes del cepario, una bacteria comercial como control positivo Bacillus subtilis (Bs) y un control negativo en blanco sin presencia de microorganismo.

Los tratamientos considerados fueron 
evaluados bajo el diseño bloques al azar, con seis repeticiones. Se bloqueó el efecto de la luz que entraba solo por un lado del invernadero. Donde la unidad experimental estuvo constituida por una maceta de $2 \mathrm{Kg}$ con una sola planta. Las cepas seleccionadas en la primera etapa fueron agrupadas a través del análisis de Clúster.

\section{Segunda etapa}

Las bacterias que presentaron un mayor potencial como promotoras de crecimiento de la planta en la primera etapa fueron seleccionadas para ser evaluadas funcionalmente in-vitro e invernadero evaluando la capacidad de las mismas como promotoras de crecimiento para seleccionar el aislado bacteriano más promisorio.

\section{Pruebas in-vitro complementarias}

Se realizaron las pruebas in-vitro a las bacterias seleccionadas de la primera etapa. Con las cepas seleccionadas de la primera etapa se realizó las pruebas cualitativas considerando los tres mecanismos funcionales: Fijación biológica de Nitrógeno, Solubilización de Fosfato y producción de ácido indol acético (AIA).

\section{Producción de Ácido Indol Acético.}

La determinación de bacterias endófitas fijadoras de Nitrógeno se realizó en base al protocolo utilizado por Dion $\mathrm{y}$ Magallón (2009).

Con un día de anterioridad a la prueba se preparó el medio Burk sólido, este se autoclavó durante $20 \mathrm{~min}$ a $121^{\circ} \mathrm{C}$ y 20 Psi. en condiciones de asepsia bajo una cámara de flujo laminar se dispensó el medio en placas Petri dejándolas reposar por 24 horas antes de su uso. Las placas con el medio Burk fueron divididas e identificadas para cada una de las cepas seleccionadas. En cada una de las divisiones, con la ayuda de un asa metálica se sembraron los aislados bacterianos. Posteriormente las placas fueron incubadas por 48 horas a $30^{\circ} \mathrm{C}$.

Asimismo, se empleó un control positivo y un control negativo, el control positivo consistió en una placa Petri sembrada con una cepa de Paenibacillus spp. fijadora de Nitrógeno de la colección del laboratorio y el control negativo donde no se sembró nada, esto con el fin de asegurar la esterilidad del medio Burk.

A partir del protocolo de Nautiyal (1999), se realizó la determinación de cepas bacterianas capaces de solubilizar fosfato. Inicialmente se preparó el medio de cultivo NBRIP con Fosfato Tricalcico al cual se añadió azul de bromofenol como indicador de $\mathrm{pH}$. Una vez autoclavado, dispensado en placas petri, bajo una cámara de flujo laminar, se sembró cada cepa bacteriana por extensión en cada respectivo cuadrante. Como control positivo se utilizó una cepa de Bacillus pumilus solubilizadora de fosfato y para el control negativo no se sembró nada, esto con el fin de asegurar la esterilidad del medio NBRIP. Posteriormente las placas fueron incubadas durante 48 horas a $30^{\circ} \mathrm{C}$. Se realizó la determinación de cepas bacterianas productoras de ácido indol acético. Para esta prueba es muy importante considerar que el AIA es un metabolito secundario producido por algunas bacterias en el periodo estacionario de crecimiento, para lo cual se sembró cada cepa en tubos con medio líquido TSB, suplementado con $5 \mathrm{mM}$ de L-Triptófano.

Se preparó el medio TSB, que después de su autoclavado y bajo una cámara de flujo laminar, se añadió L-Triptófano, esterilizado por un filtro de $0,2 \mu \mathrm{m}$. luego se dispenso $5 \mathrm{~mL}$ del medio en tubos de ensayo, después de sembrar las cepas 
bacterianas, se incubaron en un agitador orbital con temperatura de $28{ }^{\circ} \mathrm{C}$ y 100 rpm durante 7 días. También se sembró un control positivo, Bacillus subtilis cepa conocida como productora de AIA y un control negativo, en la cual no se sembró nada, esto para asegurar la esterilidad del medio de cultivo.

Transcurrido los 7 días de incubación, de cada tubo de ensayo se extrajo $1000 \mu \mathrm{l}$ de muestra en tubos Eppendorf. Luego se centrifugaron a $5000 \mathrm{rpm}$, durante 5 minutos. Para revelar el AIA en las muestras, se preparó la solución Salkowski con 24 horas de anterioridad. Para el relevado, se extrajó del sobrenadante del caldo bacteriano, colocando en placa Elisa al cual se adicionó el reactivo de Salkowski. Para su revelado se dejó la placa en absoluta oscuridad durante 15 minutos. Finalmente se reportaron como positivos para la producción de AIA los que viraron de color rosado claro a tonos rojizos.

\section{Caracterización bioquímica de las cepas bacterianas}

Para la caracterización de las cepas bacterianas seleccionadas, se utilizó el protocolo de Pérez et al. (2004). Para lo cual se realizaron las pruebas de amilasa, catalasa, hidróxido de potasio y tinción de Gram. Iniciando con la reactivación de las cepas en medio TSA y que se las incubó por 48 horas a $30^{\circ} \mathrm{C}$.

Para la prueba de amilasa se preparó el medio agar-almidón, una vez autoclavado bajo una cámara de flujo laminar se realizó la siembra de las cepas bacterianas en placas Petri, una cepa por cuadrante. Posteriormente, se colocaron en la incubadora a $30^{\circ} \mathrm{C}$ durante 24 horas. Transcurrido este tiempo se realizó el revelado con Yodo, reportándose como positivas las cepas que presentaron halos transparentes alrededor de la colonia.
Para la prueba de la catalasa, se tomó en un portaobjetos, se colocó con la ayuda de un mondadiente esterilizado la muestra bacteriana, posteriormente se añadió una gota de agua oxigenada al $3 \%\left(\mathrm{H}_{2} \mathrm{O}_{2}\right)$ sobre la muestra, se registraron como positivas las que presentan burbujeo.

Sobre un portaobjetos desinfectado con un asa bacteriana se colocó una muestra bacteriana, con ayuda de una micropipeta se añadió una gota de $\mathrm{KOH}$ al $10 \%$ sobre la muestra, para luego mezclar con un mondadiente estéril. Registrándose las positivas cuando se levantó un hilo viscoso con el mondadiente.

Para la tinción de Gram se realizó la extensión, fijación, coloración y el secado, siguiendo el protocolo estándar para la tinción de Gram. Posteriormente, se procedió a la observación de los Bacillus en el microscopio. Las cepas que se vieron rojas se registraron como Gram (-) y las cepas que mostraron el color violeta se registraron como Gram (+).

\section{Multiplicación de bacterias}

Las bacterias seleccionadas fueron multiplicadas en pequeña escala, para ello se preparó el medio de cultivo liquido TSB, dispensando $6 \mathrm{~mL}$ en cada tubo de ensayo, los mismos que se autoclavaron por $15 \mathrm{~min}$ a $121^{\circ} \mathrm{C}$ a 20 psi. Posteriormente, bajo una cámara de flujo laminar se inocularon cada uno de los aislados, el control positivo y un tubo solo con medio para el testigo en blanco. Los tubos de ensayo fueron llevados a un agitador orbital a $100 \mathrm{rpm}$ durante 7 días a temperatura ambiente.

\section{Estandarización de inóculo}

El inóculo se estandarizó a una concentración de $1 \times 10^{8}$ esporas/mL. Para lo cual se observó la concentración bacteriana con una cámara de Neubauer. Para la siembra se utilizó macetas de $2 \mathrm{~kg}$ 
de capacidad con sustrato estéril donde se sembró una semilla por maceta, al momento de la siembra se inoculo $500 \mu \mathrm{L}$ de solución bacteriana a la semilla con ayuda de una micropipeta.

Las bacterias seleccionadas de la primera etapa, conjuntamente con el control positivo y negativo, fueron evaluadas bajo el diseño experimental completos al azar con 6 repeticiones. Donde la unidad experimental estuvo constituida por un maceta de $2 \mathrm{~kg}$ con una sola planta.

En invernadero, se evaluaron las siguientes variables en ambas fases: altura de planta, longitud de la raíz $(\mathrm{cm})$, peso de la raíz (g), volumen de raíz (cc), número de tubérculos, peso de tubérculo (g), para el rendimiento el peso de tubérculos (t/ha).

Los datos de cada variable cualitativas, de la primera y segunda etapa, fueron analizados con el PROC MIXED del SAS, previa verificación de los supuestos de distribución normal y homogeneidad de varianzas bajo un modelo estadístico en diseño bloques al azar, donde se bloqueó el efecto de luz natural que se presentó en una parte del invernadero. Luego se hizo la comparación de medias de rango múltiple Tukey $(\mathrm{p}=0,05)$. Para seleccionar a las cepas con características similares, se utilizaron las medias de todas las variables de respuesta, los cuales fueron sometidas al análisis de CLUSTER de acuerdo al método de distancia máxima usando el PROC CLUSTER del SAS.

\section{Resultados y Discusión}

Los resultados observados se presentan en dos etapas. En la primera etapa se seleccionó in-vitro en laboratorio y se evaluó en invernadero las cepas bacterianas tipo Bacillus. Asimismo, en la segunda etapa se evaluaron in-vitro e invernadero las cepas seleccionadas de la primera etapa.

\section{Primera etapa}

\section{Selección in-vitro de bacterias tipo Bacillus}

Se comenzó con la activación de 39 aislados bacterianos endófitos de papas nativas. 30 aislados fueron positivos para el género Bacillus, presentando un crecimiento óptimo en el medio TSA. Estas fueron evaluadas en la primera etapa en invernadero.

El género Bacillus forma endosporas altamente resistentes a temperaturas altas $\left(80^{\circ} \mathrm{C}\right)$ dándole una ventaja competitiva muy importante en el suelo; ya que deben adaptarse a cambios bruscos de temperatura (Petersohn et al., 2001).

\section{Selección en invernadero}

\section{Altura de planta}

La altura de planta varía significativamente $(p=0,05)$ con la inoculación de los diferentes aislados. Las plantas inoculadas con los aislados 12, 146, 19, 20, 34, Bs y To fueron las más favorecidas con la inoculación, en comparación con el resto de las plantas inoculadas $11,13,137,138,145,150,1 b$, 2, 24, 27, 29, 3, 32, 38, 3a, 45, 46, 47, 48, 49, 51, 52, 56, 6 y 9 presentándose con altura de planta menos desarrollado (Figura 1). El aislado 6 con $32,83 \mathrm{~cm}$. planta fue el que menos desarrolló en altura de planta. 


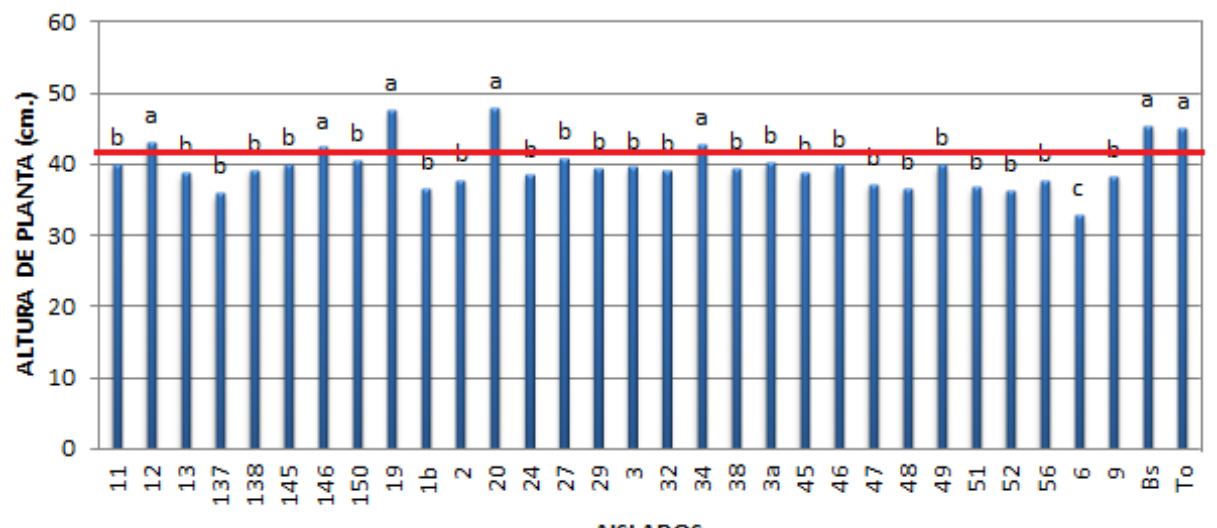

El uso de microorganismos, rizobacterias promotoras del crecimiento de plantas pueden provocar una serie de efectos benéficos en las plantas, especialmente sobre el crecimiento de las raíces y parte aérea, debido a un incremento en la disponibilidad y captación de nutrientes como fosforo, nitrógeno, potasio y micronutrientes (Kloepper et al., 1980; Vessey, 2003).

Plantas inoculadas con aislados de Bacillus, mostraron un efecto que fue relacionado con el grado de especificidad huésped-aislado bacteriano, lo que permitió mejor absorción de elementos esenciales, como el $\mathrm{N}$ y el $\mathrm{P}$ encontrados en la planta, los cual es probablemente junto con las fitohormonas, que excretan las raíces tienen una acción fisiológica, favorable provocando un mayor desarrollo de la parte aérea del cultivo.

\section{Longitud de raíz}

La longitud de raíz fue similar con la inoculación de los aislados; sin embargo, el aislado $1 \mathrm{~b}$ favoreció relativamente en longitud de raíz $(43.5 \mathrm{~cm})$, en comparación a los demás aislados incluyendo al Testigo y B. subtilis (36.33 $\mathrm{cm}$ y $37.5 \mathrm{~cm}$ respectivamente) y el que presento menor desarrollo fue el aislado $146(34.73 \mathrm{~cm})$.

Investigaciones sobre el uso de Bacillus han mostrado incrementos en el área superficial y en el largo radicular, esto contribuye el potencial de este microorganismo como alternativa de biofertilizante. También reportaron que ciertas cepas de Rhizobium inoculadas en plántulas de lechuga (Lactuca sativa L.) aumentaron su crecimiento debido a la producción de ácido indol acético (AIA), hormona vegetal que promueve el desarrollo radical o vegetativo (Peña y Reyes 2007).

\section{Peso de raíz}

El peso de la raíz de las plantas inoculadas fue similar; sin embargo el aislado 13 favoreció relativamente con mayor peso radicular $(37.72 \mathrm{~g})$ en comparación a los aislados Bs y To (25.11 y $28.32 \mathrm{~g}$ respectivamente).

El éxito en la promoción del crecimiento de las plantas, cuando se introducen bacterias benéficas depende, en gran medida, de un establecimiento oportuno y de su persistencia a lo largo de la estación de crecimiento de la raíz (Schippers et al., 1987). Uno de los efectos más importantes es la modificación de la morfología de la raíz, que incluye una fitoestimulación de este órgano y un incremento significativo en la formación de pelos radicales (Dobbelaere et al., 1999). 


\section{Volumen de raíz}

Para la variable volumen de raíz, no se observaron diferencias significativas $(p=0,005)$ entre los aislados. Sin embargo; el aislado 32 desarrollo relativamente mayor volumen de raíz (32,83 mL) en comparación a 26,83 mL desarrollado con la inoculación de la bacteria comercial (Bs) y $26,67 \mathrm{~mL}$ con el testigo (To) sin inóculo.

Los principales efectos de las bacterias promotoras del crecimiento sobre las gramíneas se han asociado con efectos en la emergencia, en el desarrollo de la raíz y efectos en el rendimiento. Con Azospirillum, los cambios favorables en las plantas, en general, se han atribuido a cambios en la absorción de $\mathrm{NO}_{3}, \mathrm{NH}_{4}$, $\mathrm{PO}_{4}, \mathrm{~K}$ y $\mathrm{Fe}$, lo cual incrementa la acumulación de minerales en hojas y tallos. Se ha sugerido que el incremento en la absorción de minerales se debe a un incremento general en el volumen de las raíces y no a un mecanismo más eficaz de absorción de iones (Bowen y Rovira, 1999).

\section{Número de tubérculo}

Para el número de tubérculos desarrollados por la planta fue similar con la inoculación de los diferentes aislados bacterianos. Sin embargo, entre los aislados que relativamente favorecieron el desarrollo de numero de tubérculos fue el aislado 34 con un promedio de 12,17 unidades, en relación a $B$. subtilis $(\mathrm{Bs})$ con 7,83 y el testigo sin inoculo (To) con 7,5 unidades. Por otro lado, el aislado que favoreció menor desarrollo fue el aislado 20 con 6,17 unidades.

En otros estudios en yuca el rendimiento agrícola mostró incrementos entre 20-54 $\%$, lo que también se evidencia en sus indicadores más cercanos, como el número de tubérculos por planta (entre $11-43 \%$ ) y el diámetro de estos (entre 15$19 \%)$. comprobándose nuevamente el efecto beneficioso sobre el cultivo de la papa. Así, en relación con la calidad de los tubérculos cosechados, se observaron diferencias significativas en todos los calibres muestreados con un incremento promedio entre $18-39 \%$ y $26-42 \%$ en el número y peso de frutos provenientes de plantas inoculadas, en comparación con plantas controles y la producción de frutos (Dibut et al., 2004; Gravel et al., 2007).

\section{Peso de tubérculo}

El peso de tubérculos varió $(\mathrm{p}=0,05)$ con la inoculación de los diferentes aislados. Así, las plantas de papa presentaron favorablemente mayor peso de tubérculo con la inoculación de los aislados 12, 13, $137,138,145,146,150,19,1 b, 27,29$, $32,34,38,3 a, 45,46,47,48,49,52,6,9$ y Bs; entre ellos el mas favorecido en peso de tuberculo fue el aislado 145 con $57,26 \mathrm{~g}$, en relacion al testigo (To) que presento menor desarrollo de tubérculos con $38,77 \mathrm{~g}$ de peso (Figura 2). 


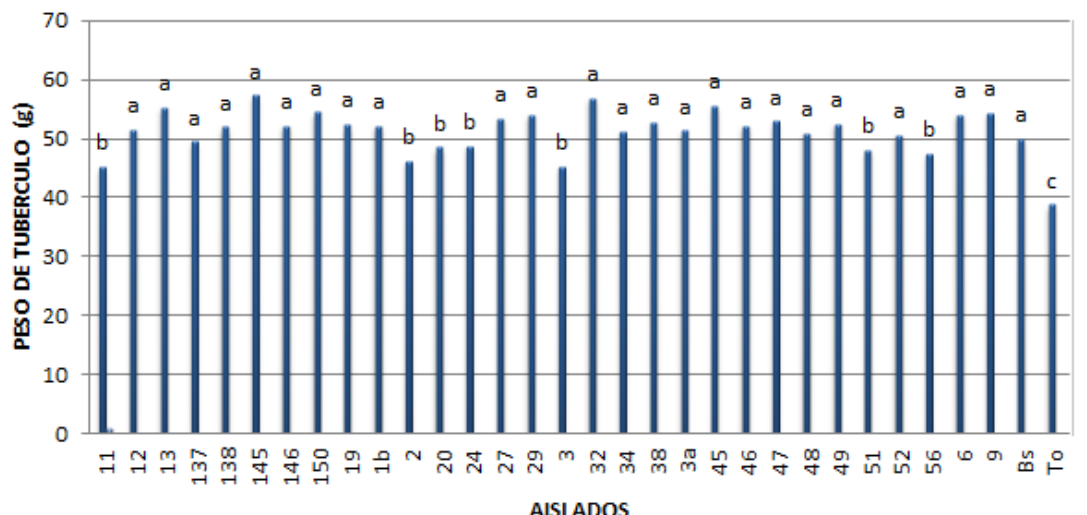

Figura 2. Variación de peso de tubérculo por planta de papa por efecto de los aislados bacterianos.

Resultados similares fueron encontrados por Soler (2012), reportando mayor formación de tubérculos ( $\mathrm{g}$ ) en las plantas inoculadas con microorganismos endófitos, comparadas con las plantas de control (plantas sin inocular).

\section{Rendimiento}

Se determinó diferencias $(\mathrm{p}=0,05)$ en el rendimiento con la inoculación de los diferentes aislados bacterianos. El mayor rendimiento se observó con la inoculación de los siguientes aislados: 12, 13, 137, $138,145,146,150,19,1 b, 27,29,32,34$, 38, 3a, 45, 46, 47, 48, 49, 52, 6, 9 y Bs. La planta que presentó el mayor rendimiento fue 2,04 t/ha con la inoculación del aislado 145. En comparación al aislado To con 1,39 t/ha que tuvo el menor rendimiento (Figura 3 ).

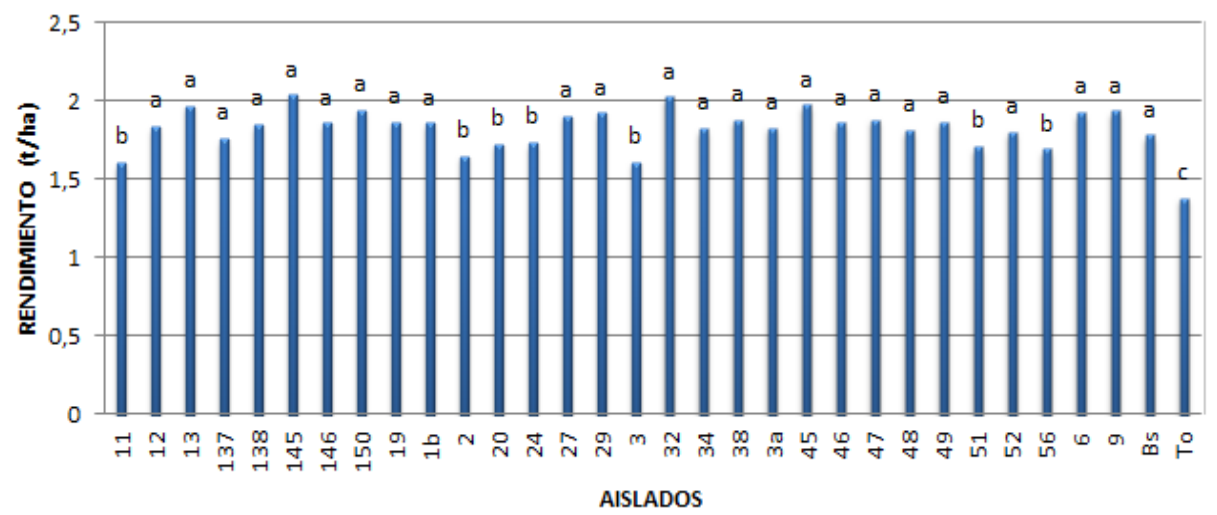

Figura 3. Variación de rendimiento de planta de papa por efecto de los aislados bacterianos.

Resultados similares obtuvieron en semillas de papa donde se observaron a los inóculos promovieron el crecimiento 
del peso seco de las raíces, en $22 \%$, y en tubérculos $80 \%$, teniendo mayor rendimiento bajo condiciones de invernadero. Posiblemente porque los microorganismos presentan la capacidad de producir auxinas, las cuales son sustancias con efecto regulador sobre el crecimiento de la planta, estando íntimamente relacionado con los procesos de fructificación de las mismas (Srivastava y Handa, 2005). Por lo tanto, la inoculación con los aislados bacterianos podría favorecer el desarrollo de tubérculos de papa y a la vez también el rendimiento.

\section{Análisis clúster de 32 aislados bacterianos de Bacillus}

Los 32 aislados de bacterias pueden agruparse en 3 grupos (Figura 4).

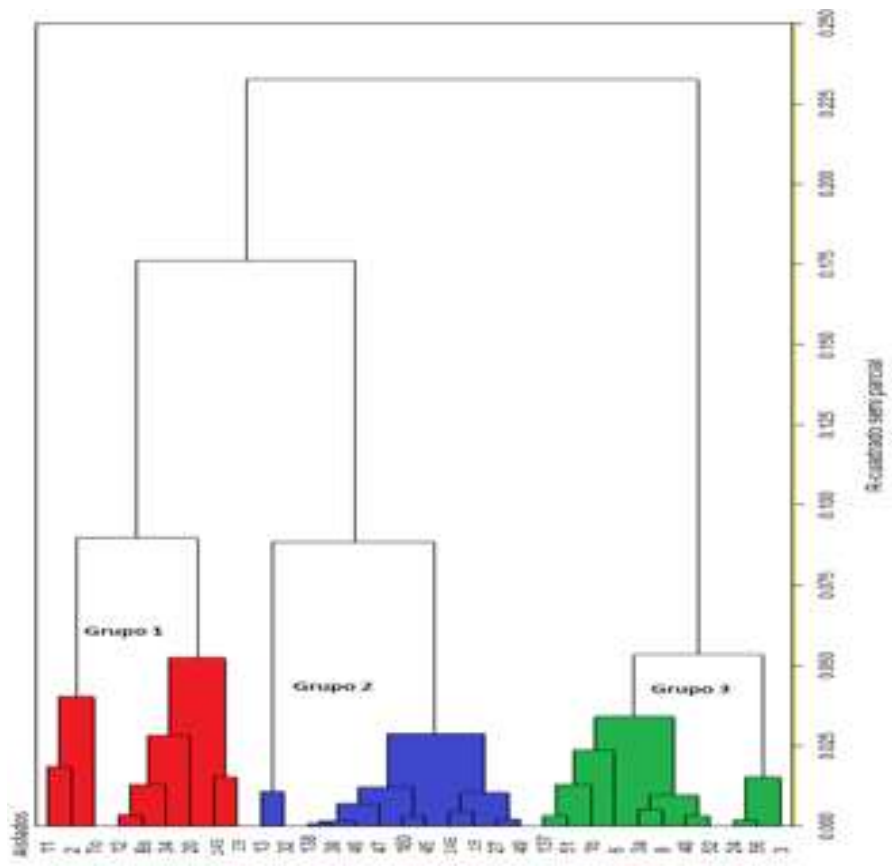

Figura 4. Dendrograma de agrupamiento de 32 aislados bacterianos.

Donde el primer grupo está compuesto por los aislados: 11, 2, To, 12, Bs, 34, 20, 146 y 49, caracterizándose principalmente por mayor desarrollo en altura de planta y no así en las demás variables, no siendo favorecido para las demás variables

El segundo grupo, está compuesto por los aislados: 13, 32, 138, 38, 46, 47, 150, 45, $145,29,27$ y 49 que tienen las características por el beneficio en desarrollo de longitud de raíz, peso de raíz, volumen de raíz, peso de tubérculo y rendimiento.

El tercer grupo, se encuentra integrado por los aislados: 137, 1b, 24, 3, 3a, 48, 51, 52, 56, 6 y 9. Este grupo está caracterizado por favorecer el desarrollo de número de tubérculos por planta.

De las 3 agrupaciones se seleccionó el grupo 2, debido a que favoreció en mayor 
proporción el desarrollo de las características fenotípicas del cultivo de la papa.

\section{Segunda etapa}

Esta etapa se inició con los mejores aislados de la primera etapa $(13,19,27$, $32,38,45,46,47,138,146$ y 150), las cuales se evaluaron in-vitro e invernadero en su desarrollo vegetativo.

\section{Pruebas funcionales}

\section{Prueba de Fijación de Nitrógeno}

Los aislados bacterianos que fueron positivos para la Fijación de Nitrógeno fueron 27, 46, 47, 38, 45, 13, 32, $146 \mathrm{y}$ 150. Por lo que estas bacterias podrían utilizarse como promotores de crecimiento en la agricultura. Como respuesta positiva a este mecanismo a través del crecimiento de la colonia en el medio Burk, ya que este medio tiene la característica de contener poca fuente de nitrógeno, de manera que las bacterias que desarrollan bajo este medio tienen la capacidad de reducir el nitrógeno gaseoso $\left(\mathrm{N}_{2}\right)$ para producir $\mathrm{NH}_{4}{ }^{+}$(amonio), que después sirve para la biosíntesis de aminoácidos (Servin y Dion, 2009). Lara et al. (2007), indican que el nitrógeno molecular que existe en la atmosfera no es fácilmente asimilable por los vegetales debido a que el triple enlace que unen los átomos que forman la molécula es difícil de romperse, la única forma de aprovechamiento es mediante el proceso metabólico conocido como Fijación Biológica de Nitrógeno (FBN). El proceso que convierte el nitrógeno en amoniaco lo hacen gracias a la actividad del complejo enzimático llamado nitrogenasa.

\section{Prueba de solubilización de fosfato}

Los aislados que fueron positivos para la solubilización de fosforo fueron 27,46 , 47, 146 y 150 del total de 11 aislados. La solubilización de fosfatos, se da por la secreción de ácidos orgánicos tales como el láctico, oxálico y cítrico por parte de los microorganismos. En los medios utilizados para establecer la actividad fosfato solubilizadora in-vitro se desarrollan zonas claras alrededor de las colonias microbiales, las cuales indican un viraje en el pH del medio a causa de la síntesis de los ácidos mencionados anteriormente (Mehta y Nautiyal, 2001).

\section{Determinación de aislados bacterianos productores de ácido indol acético (AIA)}

A través de la prueba de producción de ácido indol acético, existe un cambio de coloración en el medio desde tonos rosados a rojizos de los aislados que producen ácido indol Acético, en cambio en las que no produjeron no se observó cambios en la coloración. Por lo tanto en la presente investigación los aislados 27 , 45 y 146 son productoras de AIA. Los reguladores de crecimiento vegetal (PGRs) son sustancias orgánicas que influencian la fisiología y desarrollo de la planta a concentraciones muy bajas (García et al., 2005). Las bacterias habitantes de la rizosfera pueden influenciar el crecimiento de las plantas contribuyendo con el pool endógeno de PGRs en estas, como las auxinas, entre las que se encuentra el Ácido IndolAcético (AIA) (Patten y Glick, 2002). De esta forma, el AIA bacteriano estimularía el desarrollo del sistema radical y el crecimiento general de la planta huésped. Al mismo tiempo, incrementó en la producción de metabolitos vegetales, utilizados por las bacterias para su propio crecimiento, pondría de manifiesto un beneficio recíproco en la relación plantabacteria.

\section{Pruebas Bioquímicas}

Los mismos aislados bacterianos a los que se les hicieron las pruebas 
funcionales, fueron caracterizadas mediante las diferentes pruebas bioquímicas: Catalasa, Hidróxido de Potasio, Amilasa y Tinción de Gram.

\section{Prueba de catalasa}

La catalasa es una enzima que descompone el peróxido de hidrogeno $\left(\mathrm{H}_{2} \mathrm{O}_{2}\right)$ en agua y oxígeno. El peróxido de hidrogeno se forma como uno de los productos finales del metabolismo aerobio de los hidratos de carbono. Si se permite que se acumule resulta letal para la célula bacteriana, dentro del género Bacillus existen bacterias anaeróbicas y aeróbicas facultativas y la mayoría son catalasa positiva (Prescott, 2004). En la presente investigación los 11 aislados seleccionados fueron positivos, lo cual confirma una característica del género Bacillus.

\section{Prueba de hidróxido de potasio (KOH)}

Se observó la formación de una suspensión sumamente viscosa, que al levantarla con una asa, formó un hilo de aspecto mucilaginoso, esta reacción es una prueba previa a la tinción de Gram ya que se puede deducir anticipadamente si los aislados bacterianos son Gram positivo o Gram negativo (Prescott, 2004). En la presente investigación el aislado 13 dio positivo del total de 11 aislados bacterianos, evidenciando que pertenece al grupo de Gram positivas; confirmando el resultado en la prueba de tinción de Gram.

\section{Prueba de Amilasa}

La presencia de un halo transparente alrededor de la colonia indicó que la prueba es positiva, es decir, que el aislado bacteriano ha hidrolizado el almidón mediante la amilasa. A esta prueba los 11 aislados fueron positivos.
La producción de amilasas en el género Bacillus está relacionada con la complejidad, naturaleza y concentración de la fuente de nitrógeno, regulándola de manera positiva o negativa. Las fuentes de nitrógeno complejas más estudiadas para la producción de amilasas en especies de Bacillus son extracto de levadura y peptona, aunque la utilización de aminoácidos y $\mathrm{Ca}^{+2}$ en el medio de cultivo puede incrementar la producción (Premila y Dhandayuthapani 2013; Thippeswamy et al., 2006).

\section{Prueba de tinción de Gram}

Tanto las bacterias Gram positivas como las Bacterias Gram negativas se presentan morfológicamente como cocos o bacilos, sin embargo, al ejecutar tinción de Gram en estas para identificar su grupo taxonómico, las Gram positivas se tiñen de color violeta, mientras que las Gram negativas se tiñen de color rosado.

Mediante la tinción de Gram se identifican bacterias Gram positivas, esto se debe a que gracias a que contienen una pared gruesa de peptidoglicano y gran cantidad de ácidos teicóicos que permiten fijar y retener rápidamente el colorante inicial el cual es el cristal violeta, y además son resistentes a la decoloración. Lo contrario ocurre en el caso de las Gram negativas, las cuales poseen una pared delgada con menos cantidad de peptidoglicano y lípidos, la cual requiere de un colorante de contra tinción como la safranina o la fucsina, en este caso, el colorante inicial (cristal violeta) es fácilmente retirado en la decoloración con alcohol, debido a que su delgada pared celular no lo retiene.

Wang et al. (2007). menciona que todo el género de Bacillus pertenece al grupo de Gram positivas, confirmando la teoría, los 11 aislados bacterianos estudiados dieron 
un resultado de Gram positivo, la cual es característica del género.

\section{Resultados en invernadero}

Los mejores aislados bacterianos de la primera fase, fueron inoculados en tubérculos de papa en invernadero, para confirmar su eficiencia en el desarrollo vegetativo.

\section{Altura de la planta}

Para altura de planta se estimaron diferencias, entre los aislados bacterianos
$(\operatorname{Pr}=0,05)$, donde la altura de la planta de papa incrementó a través del tiempo.

Durante el desarrollo fenológico de las plantas, el crecimiento fue ascendente a través del tiempo con la inoculación de las diferentes aislados (Figura 5). Los aislados que presentaron mayor altura de planta fueron: 19, 45, 46, 47, 138, 146, 150 y Bs, en comparación al resto de los aislados bacterianos: 13, 27, 32 y 38 que presentaron menor altura de planta en la que se encuentra el testigo sin inóculo (To).

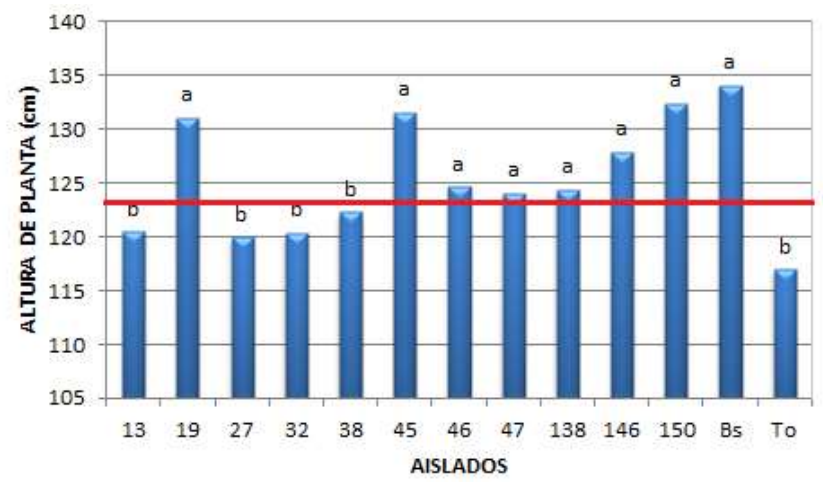

Figura 5. Variación de la altura de planta de papa por efecto de los aislados bacterianos.

En años recientes ha demostrado las ventajas de la asociación Bacillus en cereales, con resultados importantes en la estimulación del crecimiento de plantas debido a las ganancias en nutrientes por la extracción a partir del suelo, Rodríguez (2002). Los efectos más sobresalientes de algunos aislados bacterianos sugieren que posiblemente existió un sinergismo entre el hospedante y los simbiontes, lo que permitió mejor absorción de elementos esenciales, como el $\mathrm{N}$ y el $\mathrm{P}$ encontrados en la planta, los cuales probablemente junto con las fitohormonas, que excretan las raíces tienen una acción fisiológica, favorable provocando un mayor desarrollo de la parte aérea del cultivo (Arshad y Frankenberger, 1998). Por lo que el aislado 150 con $132,37 \mathrm{~cm}$ junto a los 6 aislados que presentaron mayor altura de planta, podrian ser consideradas como inoculantes para un mejor desarrollo del cultivo de papa.

\section{Longitud de raíz}

Para la variable longitud de raíz, también se observaron diferencias significativas entre los aislados bacterianos $(\mathrm{Pr}=0,0008)$, lo cual indica que la longitud de raíz vario con la inoculación de los diferentes aislados.

Así las plantas de papa desarrollaron mayor longitud radicular con la inoculación de los aislados 13, 19, 27, 32, 45, 46, 47, 146, 150 y Bs (Figura 6), sin embargo, el aislado bacteriano 13 con $26,39 \mathrm{~cm}$ es el que tuvo mejor longitud de raíz en la planta, pudiendo aumentar la superficie de absorción y así una mejor 
nutrición, en comparación a los aislados 38 y 138 con $21 \mathrm{~cm}$ y $18 \mathrm{~cm}$ respectivamente. Por otra parte, a pesar de que no se inoculó en el testigo (To) este presentó mayor longitud de raíz.

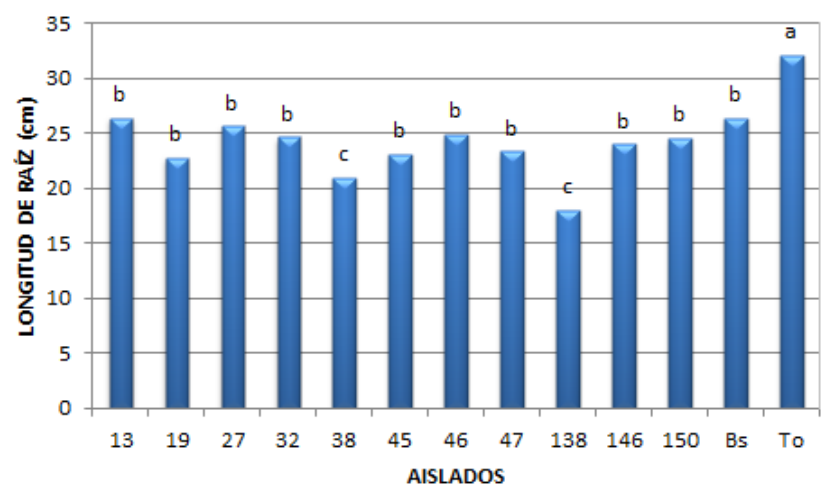

Figura 6. Variación de longitud de raíz de planta de papa por efecto de los aislados bacterianos.

El desarrollo de las raíces, es favorecido por efecto de la inoculación de los aislados, lo cual se manifiestó directamente en mayor crecimiento de la raíz del cultivo. Estos resultados concuerdan con los reportados por Pereira et al., (1988) y Kloepper et al. (1991), quienes mencionaron que las bacterias promotoras de crecimiento, se caracterizan por incrementar el desarrollo radical, lo que repercute directamente en el rendimiento del cultivo.

Desde la década de 1970, se han realizado investigaciones sobre el rol que cumplen aquellas rizobacterias de vida libre residentes de la rizosfera, benéficas por estimular el crecimiento o enraizamiento de las plantas y la resistencia a enfermedades, y que fueron denominadas PGPR; pudiendo también ejercer efectos neutrales o perjudiciales, según la concentración que alcancen en los tejidos del huésped (Bashan y Holguín, 1998); Arshad y Frankerberger, 1998; Díaz et al., 2009). Mostrando un efecto negativo a la inoculación, ya que el testigo puede sobresalir como el mejor tratamiento. Lo anterior confirma lo señalado por (Schipper et al., 1987), de que la inoculación puede tener una influencia deletérea.

\section{Peso de raíz.}

Para la variable peso de raíz, también se obtuvieron diferencias significativas entre los aislados bacterianos $(\operatorname{Pr}=0,0001)$. Por lo que el peso de la raíz vario con la

Así, los aislados que mostraron efectos benéficos en peso de raíz de la planta fueron 13, 27, 32, 38, 46, 47 y Bacillus subtilis (Bs) que presento el mayor peso con 11g (Figura 7), posteriormente los aislados 27 y 38 con un peso de $8 \mathrm{~g}$, en comparación a los aislados 45, 138, 146, 150 y el testigo (To) con 4,66 g, el aislado 19 es el que desarrollo el menor peso radicular $2,75 \mathrm{~g}$. 


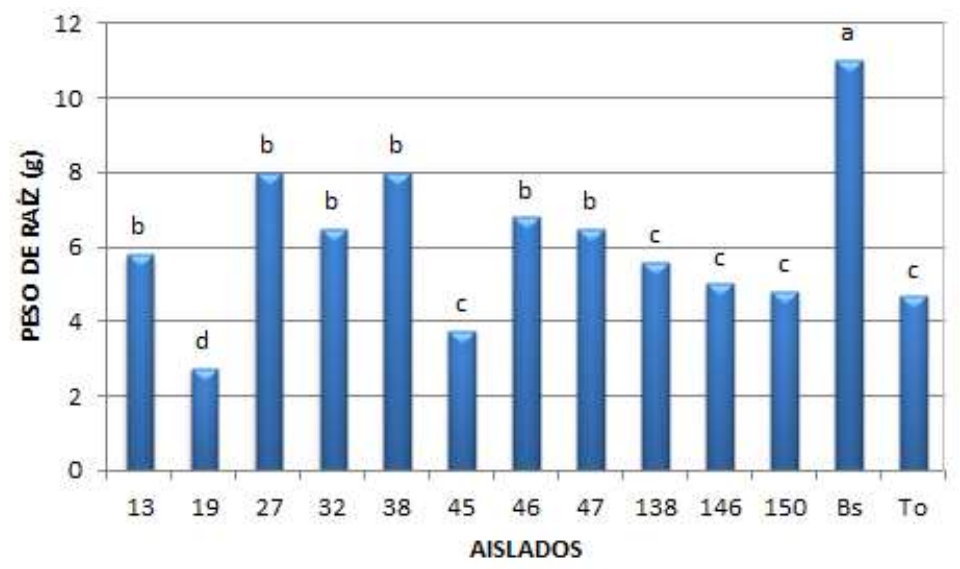

Figura 7. Variación de peso de raíz de planta de papa por efecto de los aislados bacterianos.

Varios microorganismos del suelo comunes en la rizósfera son capaces de producir fitohormonas, producción que tiene efecto sobre el crecimiento y desarrollo de las plantas. Las bacterias fijadoras de nitrógeno, estimulan la elongación de raíces y formación de raíces laterales y adventicias, causando un aumento en la superficie radical (Marko e Iglesias, 2003).

\section{Volumen de raíz}

De acuerdo con el análisis de varianza para volumen de raíz, no se observaron diferencias significativas entre los aislados $(\operatorname{Pr}=0,2493)$ sin embargo, el aislado 146 favoreció relativamente el desarrollo de mayor volumen de raíz (18,33 mL), en comparación a los demás aislados que desarrollaron menos de $12,33 \mathrm{~mL}$ incluyendo al Testigo (To) y Bacillus subtilis $(\mathrm{T}+) \quad(11,33$ y $15,60 \mathrm{~mL}$ respectivamente). La mayoría de las asociaciones microorganismo-planta ocurre a nivel de la rizósfera, porción del suelo que está fuertemente influenciada por las raíces de las plantas, mediante intercambios simbióticos con la planta, que estimulan el desarrollo del sistema radicular (Aguilar, 2003).

\section{Número de tubérculo}

Para la variable número de tubérculos, se observó diferencias significativas entre los aislados bacterianos $(\operatorname{Pr}=0,0001)$, lo cual que el número de tubérculos desarrolladas por la planta

Donde el mayor de tubérculos se observó con la inoculación de los aislados 13, 19, 45, 46, 47, 138, 146, Bs (Figura 8), en comparación al resto de los aislados 27 , 32, 38, 150 incluyendo el testigo (To), que desarrollo menor número de tubérculos. 


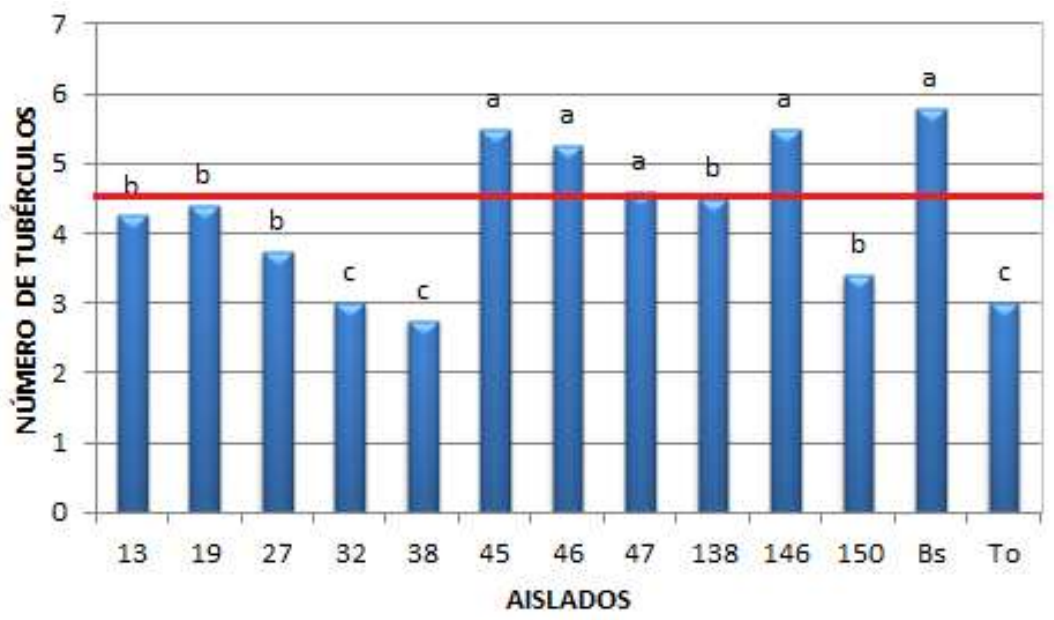

Figura 8. Variación de número de tubérculos de planta de papa por efecto de los aislados bacterianos.

Con relación al número de tubérculos, resultados similares se reportaron en otros estudios con fresa (Fragaria versca) (Esitken et al., 2010), frambuesa (Rubus idaeus) (Orhan et al., 2006) y en chile (Capsicum annum) (Datta et al., 2011), en los cuales los tratamientos de Bacillus aumentaron el número de frutos, esto puede deberse a la asociación que estos microorganismos tienen con los diferentes cultivares en los que son aplicados como cereales, hortalizas o tubérculos.

\section{Peso de tubérculo}

Al igual que para número de tubérculos para peso de tubérculo, también se estimaron diferencias entre los aislados bacterianos $(\operatorname{Pr}=0,0001)$, donde los peso variaron con la inoculación de los diferentes aislados.

Así, las plantas de papa presentaron mayor peso de tubérculos con la inoculación de los aislados 19, 27, 32, 38, 45, 46, 47, 146, 150, Bs y To (Figura 9), resaltando al mejor aislado que es el comercial Bs con $72.74 \mathrm{~g}$, seguido del aislado 45 con $71,63 \mathrm{~g}$. Los aislados que presentarón menor peso de tubérculo por planta fuerón los aislados 13 y 138 con 38,50 g y 36,40 g respectivamente. 


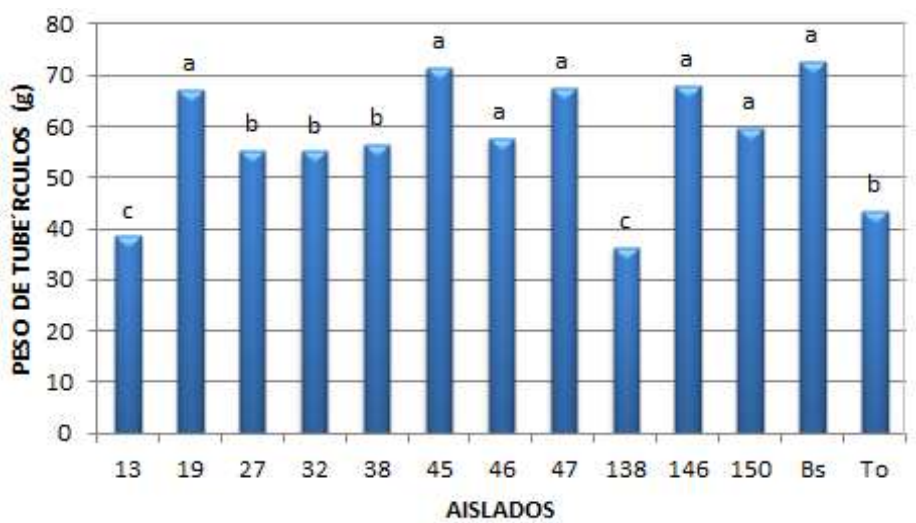

Figura 9. Variación de peso de tubérculo de planta de papa por efecto de los aislados bacterianos.

Aguilar et al. (2003), también demostraron en su investigación el beneficio que se obtiene con la inoculación de bacterias tipo Bacillus en plantas de papa, donde reportaron una diferencia significativa en cuanto a la masa (peso) de tubérculo en relación al testigo.

\section{Rendimiento}

Para la variable rendimiento, también se encontraron diferencias significativas entre los aislados bacterianos $(\operatorname{Pr}=0,0012)$, lo cual indica que el rendimiento de tubérculos fue diferente con la inoculación de los diferentes aislados bacterianos.

Donde, los aislados bacterianos que mostraron efectos benéficos en rendimiento de la planta fueron 19, 38, 45, 46, 47, 138, 146 y el Bs (Figura 10), resaltando el mejor aislado 45 con 3 t/ha con respecto a los aislados con menos rendimiento como los aislados $13,27,32$, 150, incluyendo al testigo. El aislado que desarrollo menor rendimiento fue 150 con $1.48 \mathrm{t} / \mathrm{ha}$.

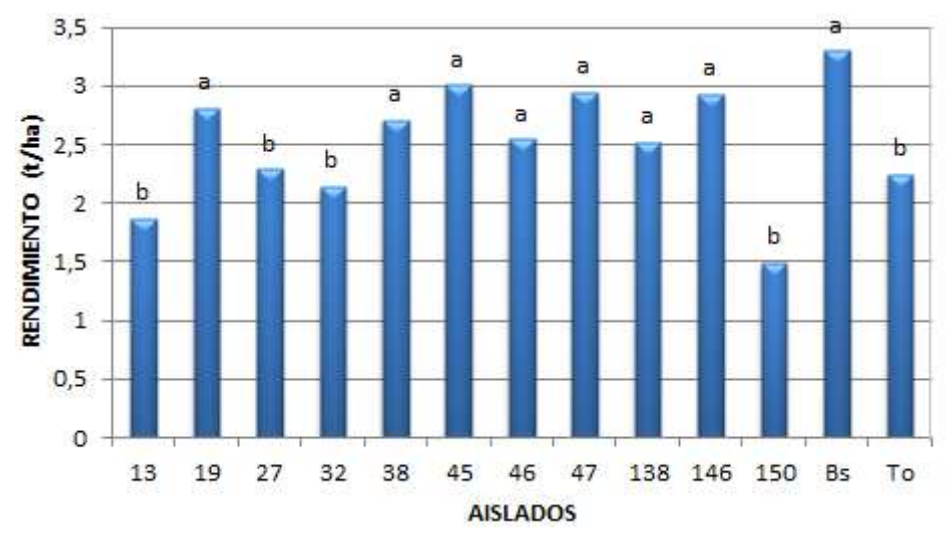

Figura 10. Variación de rendimiento de planta de papa por efecto de los aislados bacterianos. 
El rendimiento de tubérculo de papa presentó un incremento notable con la inoculación de bacterias tipo Bacillus, presentando un incremento de $68 \%$ en comparación con las plantas no inoculadas en el presente estudio. Otros estudios reportaron resultados similares, (Jiménez et al., 2001), donde anuncian que el efecto benéfico en rendimiento de la papa debido a la utilización de especies de Bacillus, sin embargo, en dichos estudios el incremento varia de $4 \%$ a $47 \%$, mientras que en la presente investigación el incremento es mayor, esto puede deberse a la concentración de bacterias en la superficie o en la raíz.
Selección de los aislados bacterianos con las mejores características como PGRB

A través del agrupamiento de aislados bacterianos (Figura 11), los 12 aislados pueden agruparse en 2 grupos, donde el primer grupo compuesto por los aislados $13,138,27,32,38$ y 46 se caracterizan por su efecto sobre el desarrollo de plantas pequeñas, menor tamaño de la raíz, menor número de tubérculos, menor peso de tubérculos/planta, menor volumen radicular y menor rendimiento; aunque, promueven ligeramente mayor desarrollo radicular.

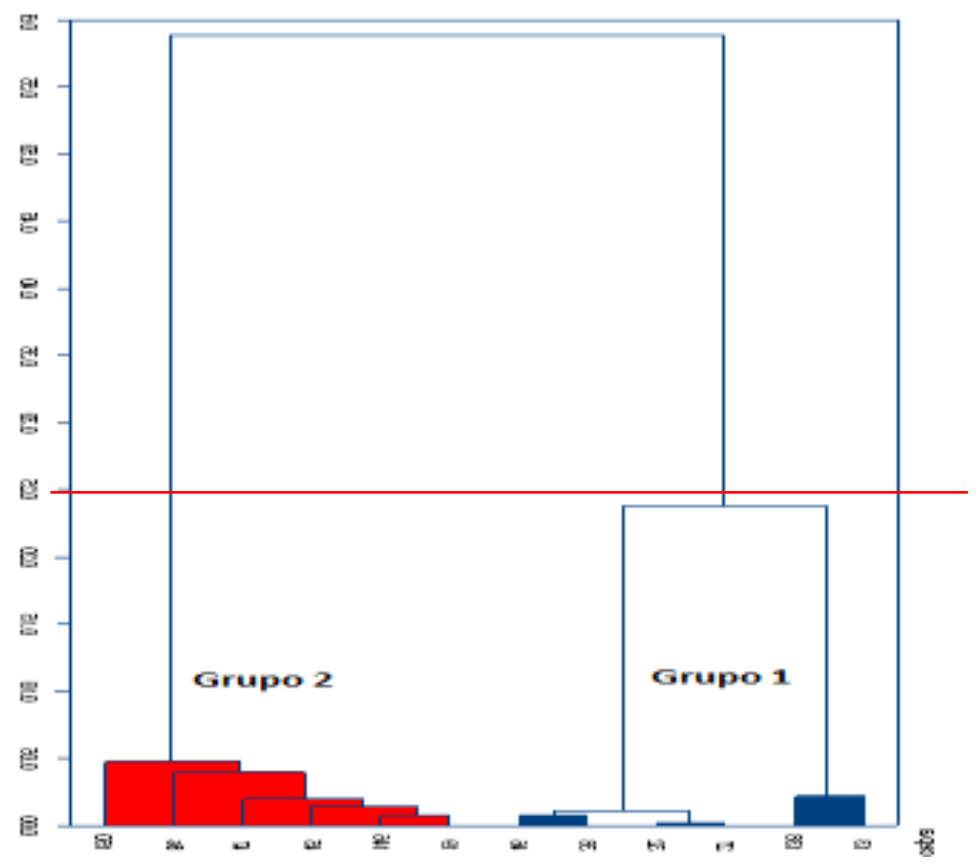

Figura 11. Dendrograma de agrupamiento de 12 aislados bacterianos. 
El segundo grupo lo conforman los aislados 19, 146, 45, 47, Bs y 150 que se caracterizan porque promueven el desarrollo de plantas más altas con mayor tamaño de la raíz, por consiguiente, mayor volumen radicular. Asimismo, promueven el desarrollo de mayor número de tubérculos con mayor peso de tubérculos/planta y con mayor rendimiento. Aunque, promueven en menor proporción el desarrollo de la raíz.

Por lo que los aislados del grupo 2 podrían ser seleccionados como promotores de crecimiento, debido a que promueven el desarrollo de características favorables como el rendimiento.

De acuerdo a los objetivos planteados y los resultados obtenidos se definió que las pruebas bioquímicas demostraron que los aislados seleccionados corresponden al género Bacillus. De una colección de los 39 aislados bacterianos provenientes de plantas silvestres de papa, 30 son aislados bacterianos del género Bacillus.Bajo condiciones de invernadero de 30 aislados bacterianos del genero Bacillus, se seleccionaron 11 aislados $(13,19,27,32$, $38,45,46,47,138,146$ у 150), como promotores de crecimiento en el cultivo de papa variedad Huaycha.

En condiciones in-vitro de los 11 aislados seleccionados como promotores de crecimiento vegetal en la primera etapa, nueve dieron positivo para fijación de nitrógeno a través del crecimiento de colonia en el medio Burk, cinco presentaron crecimiento en el medio de cultivo NBRIP y tres son productoras de ácido indol acético. Los aislados 27 y 146 presentan las tres funciones.

De los 11 aislados bacterianos, el grupo 2 conformado por los aislados 19, 146, 45, 47, 150 e incluyendo el inóculo comercial B. subtilis, presentó mayor efecto sobre el desarrollo de la planta. Destacándose al aislado 45 por presentar mayor altura de planta y desarrollo de tubérculo con un rendimiento de $3 \mathrm{t} / \mathrm{ha}$ de papa.

\section{Conflicto de intereses}

La presente investigación no presenta ningún conflicto de interés con las instituciones donde fueron realizados los experimentos.

\section{Referencias citadas}

Aguilar, C.; Arau, G.; Grageda, R.; Torres, J. (2003). Uso de bacterias benéficas para mejorar la producción de papa. Métodos de investigación. 3 de Junio de 2003, 12 CD.

Arshad, M; Frankerberger, WT. (1998). Plant Growth-Regulating Substances in the Rhizosphere: Microbial production and functions. Advances in Agronomy 62: $45-151$.

Bowen, G. D.; Rovira, A. (1999). The rhizosphere and its management to improve plant growth. Advances in Agronomy V 66: 1-102.

Crespo, F.; Bellot, S. (2003). La agricultura Sostén de la Economía. Disponible en: http://www.Nuevaeconomia.com.bo/docs/ 05agrop. Pdf, 02/03/05.

Díaz, K.; Valiente, C.; Martinez, M.; Castillo, M; Sanfuentes, E. (2009). Rootpromoting rhizobacteria in Eucalyptus globulus cuttings. World Journal of Microbiology and Biotechnology 25 (5): 867.

Dibut, B.; Martinez, R.; Ortega, M.; Rios, Y.; Fey, L. (2004). Presencia y uso de microorganismos endófitos en plantas como perspectiva para el mejoramiento de la producción vegetal. Cultivos Tropicales, vol. 25, núm. 2, 2004, pp. 1317 Instituto Nacional de Ciencias Agrícolas La Habana, Cuba. 
Dion, P.; Magallón, C. (2009). Curso práctico-teórico de microbiología agrícola. Importancia de los microorganismos promotores de crecimiento vegetal para los pequeños productores de Bolivia. Fundación PROINPA, Cbba.-Bolivia. 66p.

Dobbelaere, S.; Croonenborghs, A.; Thys, A.; Vande B.; Vanderleyden, J. (1999). Phytostimulatory effect of Azospirillum brasilense wild type and mutant strain altered in IAA production on wheat. Plant Soil 212: 155-164.

Esitken, A.; Yildiz, H. E.; Ercisli, S.; Figen, M.; Turan, M.; Gunes, A. (2010). Effects of plant growth promoting bacteria (PGPB) on yield, growth and nutrient contents of organically grown strawberry. 124(1):62-66.

García, I. N.; Hynes, R. K.; Nelson, L.M. (2005). Role of cytokinins in plant growth byrhizosphere bacteria. PGPR: Biocontrol and fertilization. Pg 173-195.

Gravel, V.; Antoun, H.; Tweddell, R.J. (2007). Growth stimulation and fruit yield improvement of greenhouse tomato plants by inoculation with Pseudomonas putida or Trichoderma atroviride: possible role of indole acetic acid (IAA). Soil Biol. Biochem. 39:1968- 1977.

Jiménez, D. R.; Virgen, C. G.; Tabares, P. V.; Olalde, F.S. (2001). Bacterias promotoras del crecimiento de plantas: agro-biotecnologia. Avance y Perspectiva, 395.

Kloepper, J.; Leong, J.; Teintze, M.; Sichroth, M. (1980). Enhanced plant growth by siderophores produced by plant growth-promoting rhizobacteria. Nature 286, 885-886.

Kloepper, J.W., R.M. Zablotowicz, E.M. Tipping, Lifshitz. R. (1991). Plant growth promotion mediated by bacterial rhizosphere colonizer. pp. 315-326. In: D.L. Keister y P.B. Cregan (eds.). The rhizosphere and plant growth.Kluwer. Dordrecht, The Netherlands.

Lara, C.; Villalba, M.; Oviedo, L. (2007). Bacterias asimbióticas de nitrógeno de la zona agrícola de San Carlos. Córdoba, Colombia. Revista Colombiana Biotecnologia. 9: 6-14.

Marko, J.; Iglesias, M.C. (2003). Utilizacion de Azospirilum Az 39 INTA e inoculante mixto comercial en el cultivo de soja fertilizada. Cátedra de Microbiología Agrícola - Facultad de Cs. Agrarias - UNNE. Resumen: A-053. Argentina (inédito) 1-3p.

Mehta, S.; Nautiyal, S. (2001). An efficient Method for qualitative screening of phosphate- solubilizing bacteria.Current Microbiology.51-56.

Nautiyal, S. (1999). Stress induced phosphate solubilization in bacteria isolated from alkaline soils. FEMS Microbiol. Let. 291-296p.

Orhan, E.; Esitken, A.; Ercisli, S.; Turan, M.; Sahin, F. (2006). Effects of plant growth promoting rhizobacteria (PGPR) on yield, growth and nutrient contents in organically growing raspberry. Scientia Horticulturae. 111(1):38-43.

Ortuño, N.; Claros, M.; Angulo, V.; Navia, O.; Meneses, E.; Castillo, J. (2010). Biofertilizantes artesanales con microorganismos rizosfericos nativos para una producción orgánica de quinua en Bolivia. Congreso de producción orgánica, Chillan-Chile.

Patten, C.L.; Glick, B.L. (2002). Role of Pseudomonas putida Indole acetic Acid in Development of the Host Plant Root System. Applied and environmental microbiology, 68:3795-380. 
Peña, H. B.; Reyes, I. (2007). Aislamiento y evaluación de bacterias fijadoras de nitrógeno y disolventes de fosfatos en la promoción del crecimiento de la lechuga (Lactuca sativa L.). Interciencia 32:560- 565.

Pereira, J.A.R.; Cavalcante, V.A.; Baldani, J.I.; Dobereiner, J. (1988). Sorghum and rice inoculation with Azospirillum sp. Y Herbaspirillum seropedicae in field. Plant Soil 110: 269 274.

Pérez, G. (2008) propiedades nutricionales de la papa. Disponible en: http://gisellacuisine.blogspot.com/2008/0 2/propiedades-nutricionales-de-lapapa.htmL.

Petersohn, A.; Brigulla, M.; Haas,S.; Hoheisel, J.; Lker, U.; Hecker, M. (2001). Global Analysis of the General Stress Response of Bacillus subtilis. Journal of Bacteriology. 183: 5617-5631.

Prescott, L. (2004). Microbiologia. 5ta. Ed. Editorial McGraw-Hill Interamericana.Madrid-España.

Premila, S. J.; Dhandayuthapani, K. (2013). Optimization of $\alpha$-amylase production of Bacillus stearothermo philus KDP from Sago Industry Waste. Int. Journal Applied BioResearch 16:1721.

Servin, P.; Dion, P. (2009). Curso práctico-teórico de microbiología agrícola. Importancia de los microorganismos promotores de crecimiento vegetal para los pequeños productores de Bolivia. Fundación PROINPA, Cbba.- Bolivia. 66 p.

Schippers, B.; A.W. Bakker; Bakker. A.H.M. (1987). Interactions of deleterious and beneficial rhizosphere microorganisms and the effect of cropping practices. Ann. Rev. Phytopathol. 25: 339-358.
Srivastava, A.; Handa, A. (2005). Hormonal regulation of tomato fruit development: a molecular perspective. Journal of Plant Growth Regulation. 24: 6-82.

Thippeswamy, S.; Girigowda, K.; Mulimani, V.H. (2006). Isolation and identification of amylase producing Bacillus sp. from dhal industry waste. Indian Journal of Biochemistry and Biophysics 43:295-298.

Vessey, J. K. (2003). Plant growth promoting rhizobacteria as biofertilizers. Plant and Soil 255: 571-586. 